\title{
When Is a Causative Situation not Mapped to a Gausative Construction Proper? The Gase of Hupa
}

\author{
Ramón Escamilla * \\ (University of Central Arkansas, USA)
}

\begin{abstract}
This work interrogates why certain real-world events that meet criteria for being considered causative events cannot be expressed using Hupa's morphological or syntactic causative constructions, but must be encoded using one of two periphrastic constructions in which the Causer or cause is not marked as an argument. Based on fieldwork with a native speaker, I probe into these two periphrastic constructions in depth, accounting for their distributions through an appeal to Næss's (2007) account of semantic transitivity.
\end{abstract}

Keywords: Hupa, Dene, causative, semantics, typology

\section{Introduction}

Hupa (ISO 639-3 [hup]) is a critically endangered language belonging to the Pacific Coast branch of the Dene family. Hupa causative constructions have been reasonably well described in the literature. Golla's (1970) descriptive grammar provides an explanation of how causative morphology operates, and this is recapitulated in Golla \& O'Neill (2001). Golla explains how some types of causative notion is an intrinsic part of some verbs, and describes lexical causatives in depth. Rice's (2000) survey of voice and valency marking in the greater Dene family provides an excellent general overview of how causativity is encoded. Escamilla (2012a) describes Hupa's syntactic causative construction, covering both semantics and compatibility with different classes of lexical verbs.

Escamilla (2012b) proceeded to problematize, though not quite account for, two periphrastic constructions in Hupa - beyond the morphological and syntactic constructions proper - and their compatibility with certain causative situations. The current work revisits these two constructions and proposes a unified analysis under Næss's (2007) account of semantic transitivity. In doing so, I appeal to data from a combination of the following: (a) Data collected in fieldwork with consultant Mrs. Verdena Parker, a native speaker of Hupa in her mid-eighties, in Oregon, USA. (b) Data culled from naturalistic narratives produced by

\footnotetext{
Acknowledgments: I thank Mrs. Verdena Parker for sharing her language and her experience.

* Dr. Ramón Escamilla: Associate Professor of Linguistics at Department of Languages, Linguistics, Literatures, and Cultures, University of Central Arkansas, USA. E-mail: rescamilla@uca.edu.
} 


\section{Ramón Escamilla}

Mrs. Parker between 2007 and 2014.

\subsection{Causativity}

What is a causative, as encoded linguistically? One early influential account is Shibatani (1976a), whose working definition models causation as consisting minimally of a causing microevent and a caused microevent, and a dependency relation between these two events believed (by the Speaker) to hold. I recapitulate his three points here:

(a) An agent causing or forcing another participant to perform an action, or to be in a certain condition [;]

(b) The relation between [the] two events [= the causing event, and the caused performing/being event] is such that the speaker believes that the occurrence of one event, the "caused event", has been realized at 2 , which is after 1 , the time of the "causing event" [;]

(c) The relation between the causing event and the caused event is such that the speaker believes that the occurrence of the caused event is wholly dependent on the occurrence of the causing event... (Shibatani, 1976a:1-2)

This set of definitional prerequisites allows for a broad set of relationships based, at least, on (a) the lexical verb, (b) the semantics of the Causer, (c) the semantics of the Causee, and (d) the semantics of the construction explicitly encoding the causal relationship. Analysts have worked to tease apart what factors (semantic or otherwise) account for the distribution of causative constructions, as well as to document what patterns actually occur. I begin by surveying a number of these works.

Comrie (1981) focuses on the typology of the syntax and semantics of causative constructions. Crucially, Comrie distinguishes between the linguistic encoding of causal relations and other, extra-linguistic concerns, such as the nature of causation itself and questions of how humans perceive causal relations. Formally, he categorizes causatives into three types, depending on the contiguity of the material encoding the causing event and the caused event. These are: (a) lexical causatives, in which the two events are expressed in a single lexical item, as in the well-discussed case of English kill; (b) morphological causatives, in which the causing event and the caused event are encoded in a single verbal complex via causative morphology, and, prototypically, morphological marking showing the status of affected arguments. Finally, in analytic causatives, in which the causing event and the caused event are encoded in separate clauses.

Song (1996) presents a typology of causatives and causation based on a database of 600 languages. Song is critical of typological work that depends on statistical inference, citing data from the Niger-Congo family that contradicts earlier claims that "languages within genera are generally fairly similar typologically" (1996:19, quoting Dryer, 1989:267). Song therefore culls data from every language with available documentation, and categorizes the various causative constructions gleaned into three classes: COMPACT, AND and PURP. 
The major difference between Song's (1996:20) analysis and Comrie (1981) and Dixon (2000), is that Song lumps the range of lexical and morphological causatives together under the label COMPACT, in which verbal material encoding the causing microevent (Song's Vcause) can be "less than a free morpheme" (e.g., bound morpheme [prefix, suffix, infix, circumfix, reduplication], zero-derivation, suppletion); or "a free morpheme" (1996:28), in which Vcause and the verbal material encoding the caused microevent (Song's Veffect) form a single grammatical unit. Song's (1996:35) AND causative is any construction in which "two clauses [are] involved" in expressing the causing and caused microevents. This, in theory, could include larger, multi-clausal expressions of causal relations which many analysts probably would not label a 'causative construction', e.g.: 'It rained yesterday, so they stayed home.' But the outer boundaries of the AND causative category are not discussed.

Dixon (2000) discusses the syntax and semantics of many types of causative constructions, and begins to address the following issue: Many languages have at least two causative constructions; leaving aside the issue of lexical causatives (except where zero-derivation is demonstrated to be a productive morphological process), these are usually broadly divided into 'more compact' and 'less compact'. Some examples are Comrie's straightforward 'morphological' vs. 'syntactic', or Song's (1996) COMPACT vs. AND constructions. Where two or more constructions are available, what factors govern a Speaker's choice?

Earlier works attempted to summarize the semantic differences under the useful rubric of the "Iconicity Principle" (see Huang \& Su (2005) for a succinct discussion), which posited a correlation between the degree of formal compactness of the linguistic material encoding the causative macroevent and the perceived directness of the relationship between causing event and caused event: shorter forms were posited to encode more direct causation than longer forms, as in the classic English I killed him [direct causation] vs. I let him die [less direct causation].

The Iconicity Principle is a good first step, but does not help explain fine-grained semantic distinctions. The first attempt to take the analysis further, to my knowledge, was Comrie's (1981:164-167) discussion of directness and control, which problematized the semantics of the Causer and Causee as possible factors influencing the distribution of different causative constructions. Dixon (2000:62-77) goes several steps further, identifying and fleshing out a system of 9 scalar parameters (i.e. (a) Relating to the verb: 1. State/action, 2. Transitivity. (b) Relating to the causee: 3. Control, 4. Volition, 5. Affectedness. (c) Relating to causer: 6. Directness, 7. Intention, 8. Naturalness, 9. Involvement) along which causative constructions tend to vary. Dixon applies this model to all causative constructions in a sample of over 25 languages, and notes that more formally compact causative constructions prototypically tend toward the following values on his 9 criteria: 


\section{Ramón Escamilla}

Causer acts naturally [parameter 8], intentionally [7] and directly [6]; the causee either lacks control [3] or has control [3] and is willing [4], and is only partially affected [5]. May apply only to active [1] intransitive [2] verbs [or may include some small subclass or transitives] [2], or to state verbs alone [1].

Having briefly situated the current research with respect to some of the functionaltypological literature on causativity, we now move on to Hupa.

\section{Causatives in Hupa}

I first summarize earlier works on Hupa causatives, then proceed with an account of the two periphrastic constructions mentioned in section 1.

\subsection{Golla (1970)}

Golla, in his $(1970: 76-77,176,201,204)$ descriptive grammar, describes three classes of morphologically- derived causatives:

(a) causatives from descriptive neuters with 1-classifier $n i$-whon' 'be good, beautiful' > Oni-(w)-t-whon' 'cause O to be beautiful'

(b) causatives from primary extension neuters with 1 - classifier $n a-\ldots$ ' $a$ ' 'O hangs' > na-O-t- ' $a$ ' 'hang $\mathrm{O}$ up'

(c) causatives from primary intransitive action themes ti-ch' $i d$ 'grow tired' > O-ti-t-ch'id 'tire O out'

While Golla does not generalize about the semantics of verb themes that are compatible with causative $t$-, we can make several preliminary generalizations to test based on the examples presented in Golla (1970) and Rice's (2000) suggestions. First of all, in the three cases described by Golla, $\mathrm{O}^{\mathbb{1}}$ (the Undergoer) is neither controlling nor agentive; rather, $\mathrm{O}$ is largely patientive in all cases. Second, the Causer appears to be acting directly on O. Third, none of the examples given (including the examples above, of course) involves the causativization of a base-transitive theme.

\subsection{Escamilla's (2012b) contribution: Hupa's syntactic causative}

Escamilla (2012b) laid out an analysis of Hupa's syntactic causative construction, consisting of two verbs: The first verb encodes the caused microevent (Song's (1996) Veffect), and is subject-marked for the person and number of the undergoer or Causee; the second verb encodes the causing microevent (Song's Vcause) and is always the form of the theme $O$ - $(s)$-t-chwen 'make'. The second verb introduces a second set of morphosyntactic arguments: the introduced agent (Causer) is marked as A on Vcause; the subject (old A) of the first verb (Veffect) is always co-marked as the direct object theme of Vcause (i.e., old A >

\footnotetext{
(1) Note that in citations of Dene verbal themes, $O$ refers to incorporated direct object, and not (necessarily) $O$ argument.
} 
When Is a Causative Situation not Mapped to a Causative Construction Proper? The Case of Hupa

new O). For example ${ }^{\mathbb{1}}$ :

(1) a. $t e:-n-c^{\prime} e^{\prime}$

INCEP-PF-wind.blows

'The wind blew.'

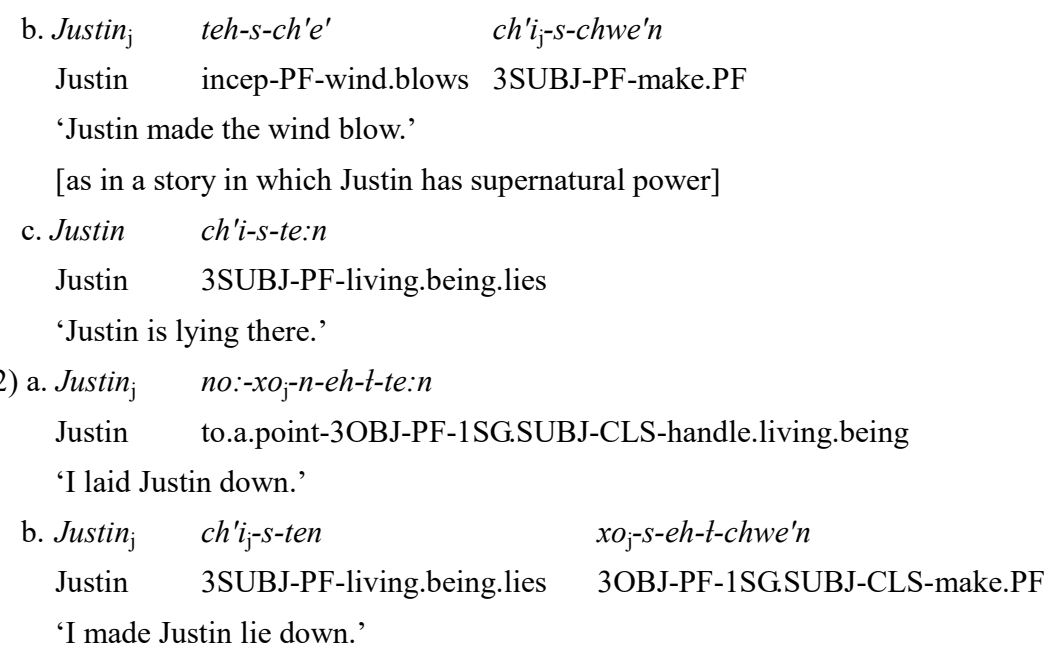

Escamilla (2012a:9) demonstrated that all basic transitive verbs causativize with this construction, and that many classes of intransitive verbs "must employ the syntactic causative construction if the Causee is perceived as having control over the caused microevent". These constructions are founded in naturalistic narratives; note simplified glosses:
(3) a. xot.dinit' $a^{\prime}$
ya:'uschwe'n
diywho' na:k'iwilxut'-tah
3.learn
3PL.SUBJ.make.3OBJ
INDEF
sewing-also
'...they [women] started teaching her sewing and stuff like that.'

$\begin{array}{cllll}\text { b. dime:n } & \text { ch'ischwe'n } & \text { 'a:di-na:' } & \text { me:w } & \text { no'k'ite:qot } \\ \text { sharp } & \text { 3SUBJ.make.PF } & \text { REFL-eye } & \text { under } & \text { 3SUBJ.place.stick }\end{array}$

'He... made sharp little sticks and placed them under his eyelids.'

Escamilla also suggests that perceived Causee control/agency (as opposed to literal control over the caused event) may be sufficient to license the syntactic construction. The following examples are given:
(4) a. na:ne:l
nah-t-to'n
doll
NON.DIR.MOTION-THM-dance
'The doll danced.'

\footnotetext{
(1) Hupa, like all Na-Dene languages, exhibits complex morphology. Most glosses have been simplified, as the internal structure of words is not crucial to the arguments in the current work.
} 


\title{
Ramón Escamilla
}

\author{
b. na:ne: $l_{\mathrm{j}} \quad$ nah-t-to'n $\quad \varnothing_{\mathrm{j}-s-e h-t-c h w e ' n}$ \\ doll NON.DIR.MOTION-THM-dance LOW.ANIM.OBJ-PF-1SG.SUBJ-THM-make.PF
}

'I made the doll dance.'

\section{The distributional divide}

Escamilla (2012a) nods at two constructions beyond the two 'true' causative constructions described above. Certain real-world situations are argued to be objectively available to causative construal (following, e.g., Shibatani's criteria) yet to be unavailable for expression via either causative construction. Observe:

(5) te:nawlay-mit w-e:-se:l

fire-with.it PF-1SG.SUBJ-warm

Lit. 'I became hot with the fire.'

[Produced for 'The fire made me (feel) hot.']

$\begin{array}{cll}\text { (6) } k^{\prime} \text { ima:w-mit } & \text { 'a-n-t'e-dzi} & n a-' i-w h \text {-di-liw } \\ \text { medicine-with.it } & \text { thus-THM-be-DIMIN } & \text { again-HABIT-1SG.SUBJ-VOICE-become }\end{array}$

Idiomatic. 'With the medicine, I became better.'

[Produced for 'The medicine makes me feel better.']

We will call this construction, which marks the would-be cause/Causer with mit 'with it', periphrastic 1. Translations of, e.g., 'The fire made me hot.' using either of the two true causative constructions are strongly dispreferred by Mrs. Parker ${ }^{1}$. The reasons that some semantic causes/Causers are incompatible with coding as arguments - as opposed to placing the cause/Causer in an adverbial or periphrastic clause - are as yet poorly understood. Note, crucially, that these situations can be construed as instances of direct causation: in (5), the heat generated by fire physically makes the Causee feel hot; in (6), it is the direct chemical functions of the medicine that cause the Causee to feel better. In operationalizing a causative situation, I also appealed to Pardeshi, who notes that such situations are "broad in nature" and are causative "regardless of their formal features". He argues that causative situations include those encoded with "causative or resultative conjunctions (e.g., because, so that) or prepositions (e.g., since, because of...)", as is the case with Hupa's periphrastic

\footnotetext{
(1) Mrs. Parker will occasionally produce sentences as the following example in translation tasks, typically after working with similar sentences for some time. Importantly, when probed at a later time (or on a different day), Mrs. Parker always rejects these as infelicitous. Since these constructions are not found in the text corpus and since she only produces them rarely and as translations of English sentences, I suspect that the underlying issue is Gil's (2001:115) "good information paradox", whereby a "more skilled informant will provide a translational equivalent that is as close as possible to the [...] source sentence, not just in meaning but also in structure".

$\begin{array}{lll}\text { k'ima:w xok'iwun yixoschwe'n } & \text { Justin } \\ \text { medicine 3.sleep } & \text { 3SUBJ.make.3OBJ } & \text { Justin } \\ \text { 'The medicine put Justin to sleep.' } & \end{array}$

'The medicine put Justin to sleep.'
} 
When Is a Causative Situation not Mapped to a Causative Construction Proper? The Case of Hupa

constructions (Pardeshi, 2016:96). Hupa's periphrastic causative constructions might be equivalent to what Hetterle (2015:190) terms content-level cause clauses, which "serve the description of real-world, direct effect relations between events" ${ }^{\text {(1) }}$.

Further, there exists a second class of events which again can be objectively argued to be available to construal as causative situations, but are unavailable to neither periphrastic 1 nor to the true causative constructions. Observe the following examples, note again that some glosses have been simplified:

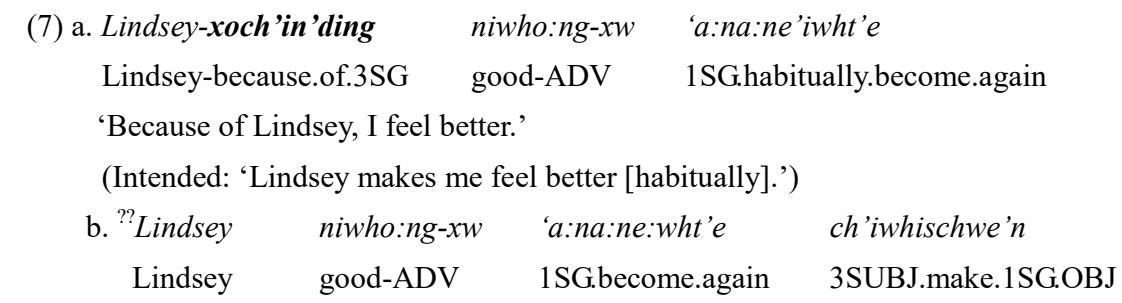

Intended: 'Lindsey made me feel better.' [syntactic causative]

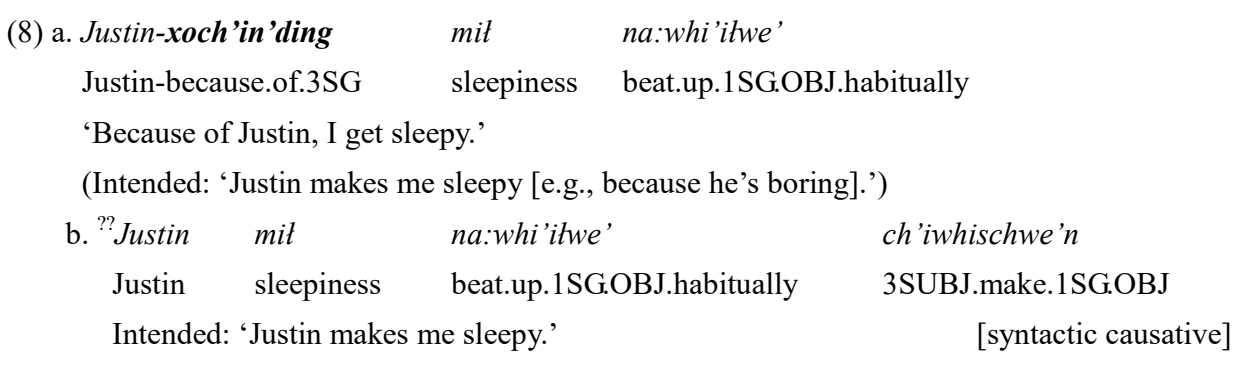

This construction marks the would-be Cause/Causer with mich'in'ding 'because of it', xoch'in'ding 'because of them[3SG] $]^{2}$,. I call this periphrastic 2 .

\section{Nass's model and periphrastic 1: Transitivity as a prototype}

The models presented above in sections 1 and 2, including Comrie (1981), Song (1996), Dixon (2000), and Escamilla (2012a) intended to account for the distribution of causative constructions within single languages and crosslinguistically. However, these models cannot account for the distributional divide between Hupa's 'true' causative constructions and the two periphrastic constructions from section 3. I will argue that Næss's (2007) model of transitivity as a radial category, though not developed to account for the encoding of causativity, nicely shoulders the bulk of the descriptive task. According to Næss, participants

\footnotetext{
(1) Hetterle (2015:192) argues that content-level cause clauses "do not serve prominent interactional purposes" and that this fact accounts for some of their distributional properties. Unfortunately, the endangerment status of Hupa makes it all but impossible to test a pragmatics-based explanation at this time.

(2) I use singular they for animate referents whose identity is unknown. mi- marks possession for a $3 \mathrm{SG}$ low animacy referent, $x o$ - for $3 \mathrm{SG}$ high animacy.
} 


\section{Ramón Escamilla}

in a two-participant event are, prototypically, crucially distinguished by three binary features:

- VOLITIONALITY ([ $\pm \mathrm{VOL}])$, the degree to which the participant acts with volition.

- INSTIGATION ([EINST]), the degree of responsibility that the participant bears for instigating the action/event (in this case, either causative, or caused).

- AFFECTEDNESS ([ $\pm \mathrm{AFF}])$, the degree to which the participant is affected.

Though these properties surely form radial categories themselves, I will for ease of exposition follow Næss's convention of treating each as a binary feature. Næss argues that feature values for Agent and Patient in a prototypical transitive clause are as follows:

Table 1. Næss's (2007) feature values for prototypical agent and patient

\begin{tabular}{c|c}
\hline Agent & Patient \\
\hline+ VOL & -VOL \\
\hline+ INST & -INST \\
\hline -AFF & + AFF \\
\hline
\end{tabular}

It will not have escaped the reader's notice that the situations encoded in the recalcitrant data above (i.e., those requiring one of the two periphrastic constructions) represent only a circumscribed subset of events: they each featured either psych verbs or verbs of sensory perception. The presence of such a verb alone, however, is not sufficient to predict compatibility with a true causative construction, e.g.,

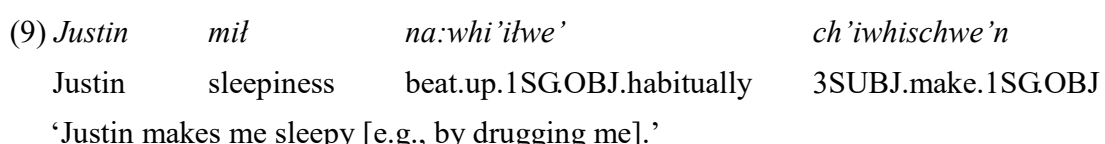

Rather than attempting to appeal to event type of verb subclass, I will argue that the split in compatibility - that is, whether an event can be expressed with the syntactic causative construction, or must be encoded with one of the periphrastic constructions - is most neatly captured by appealing to a notion of prototypical Agenthood. If we accept the proposition that direct, physical causation, with a Causer and Causee that match Næss's characterizations of prototypical Agent and Patient, respectively, in terms of feature values, then periphrastic 1 is neatly accounted for as follows: periphrastic 1 always features a Causee which is most reasonably construed to have played an instigatory role in bringing about the caused microevent on themself. Observe the following examples using construction periphrastic 1, two of which are repeated from above:
fire-with.it
PF-1SG.SUBJ-warm
(10) te:nawlay-mit w-e:-se:l
Lit. 'I became hot with the fire.'
[Produced for 'The fire made me (feel) hot.'] 
When Is a Causative Situation not Mapped to a Causative Construction Proper? The Case of Hupa

(11) k'ima:w-mit 'a-n-t'e-dzi na-'i-wh-di-liw

medicine-with.it thus-thm-be-DIMIN again-HABIT-1SG.SUBJ-VOICE-become

Idiomatic. 'With the medicine, I became better.'

[Produced for 'The medicine makes me feel better.']

(12) a. xon'ta'na:n-mil do:mina:'awhliwh

alcohol-with.it 1SG.SUBJ.habitually.forgetful

[Produced for: 'Alcohol makes me forgetful.']

b. xon'ta'na:n-mil niwho:ng-xw-ji 'a:na:ne'iwht'e

alcohol-with.it good-ADV-DIMIN 1SG.SUBJ.habitually.be

[Produced for: 'Alcohol makes me feel better.']

(13) e:bilos k'isxa:n-mit whinistexoniwh

apple tree-with.it 1SG.SUBJ.be.happy

[Produced for: 'The apple tree makes me happy.']

I propose that periphrastic 1 , in which the Causer is marked with - mit, is licensed when the following feature values hold for the two participants:

Table 2. Proposed feature values for causer and causee in periphrastic 1 construction

\begin{tabular}{c|c|c}
\hline Periphrastic 1 & Causer & Causee \\
\hline VOL & $+/-$ & - \\
\hline INST & + & + \\
\hline AFF & - & + \\
\hline
\end{tabular}

In other words, periphrastic 1 is used when the Causee/undergoer is both affected [+AFF] (expected value) and plays some participatory role in the causative microevent [+INST] (unexpected value). This idea, of a Causee participating in the causative microevent, harkens back to Hopper and Thompson's (1980) ideas about the relevance of the number of participants and the individuation of $\mathrm{O}$ to the notion of the transitive prototype: a [+INST] Causee represents a partial conflation of prototypical participant (prototypical Agent and prototypical Patient) roles, and as such constitutes a clear deviation from the prototypical direct causation event. I suggest that the marked nature of this deviation from prototypicality is encoded in the choice of a less compact construction to encode the causative event. Note, further, that the Causer's involvement is backgrounded by the use of this construction, hence the designation of $[ \pm \mathrm{VOL}]$ in the previous table: no claims about the volitionality of the Causer can be made. Observe:

\section{Periphrastic 1} $\begin{array}{llll}\text { (14) Justin na'k'iwing'aw-mit mit } & \text { na:whitwe' } \\ \text { Justin } \quad \text { 3SUBJ.sings-with.it } & \text { sleepiness } & \text { beat.up.1SG.OBJ.habitually } \\ \text { Lit. 'with Justin's singing, I got sleepy. } & \end{array}$ 


\section{Ramón Escamilla}

['Justin made me sleepy by singing.']

Again, and importantly, if the speaker wants to profile the fact that the Causer acts volitionally $[+\mathrm{VOL}]$, the syntactic causative construction must be used.

\section{Syntactic causative}

$$
\begin{array}{llcc}
\text { (15) Justin } & \text { mit } & \text { na:whi'itwe' } & \text { ch'iwhischwe'n } \\
\text { Justin } & \text { sleepiness } & \text { beat.up.1SG.OBJ.habitually } & \text { 3SUBJ.make.1SG.OBJ } \\
\text { 'Justin made me sleepy [through direct means, e.g., by drugging me].' }
\end{array}
$$

It is also crucial to note that the presence of a non-volitional Causer (a non-Agent, traditionally a Cause or Force) alone is also insufficient to license this construction, e.g.:

$$
\begin{array}{clll}
\text { (16) ninis'a:n-ma'a:dinitchwit } & \text { whi-xontaw' } & \text { yitxit } & \text { yischwe'n } \\
\text { earthquake } & \text { 1SG.POSS-house } & \text { 3SUBJ.fall } & \text { 3SUBJ.make.3OBJ }
\end{array}
$$

'The earthquake made my house fall down.'

\section{Næss's model and periphrastic 2: The Oblivious Causer}

Recall that periphrastic 2 involves a Causee argument marked with -mich'in'ding/ -xoch 'in'ding 'with it/them'. Næss's model is useful but not in itself sufficient to account for the distribution of this construction. The notion of deviation from a prototype is, I argue, still key: in situations that map felicitously to periphrastic 2, the Causer is always [+VOL] with respect to the causative microevent, but is oblivious to the causative nature of the action. That is, they are volitional Agents, but not volitional Causers. Observe the following tokens:
(17) Lindsey-xoch'in'ding
niwho:ng-xw 'a:na:ne'iwht'e
Lindsey-because.of.3SG
good-ADV 1SG.habitually.become.again
'Because of Lindsey, I feel better.'
[For: 'Lindsey makes me feel better [habitually].']

Crucially, (17) is judged infelicitous if Lindsey is acting purposefully in order to cheer the speaker up. Also:
(18) Justin-xoch'in'ding
mit
na:whi'itwe'
Justin-because.of.3SG
sleepiness
beat.up.1SG.OBJ.habitually
'Because of Justin, I get sleepy.'

Again, crucially, (18) cannot be uttered if Justin's aim is to bore the speaker.

In addition, based on a pattern of metalinguistic comments from Mrs. Parker, it seems that periphrastic 2 is used to index not only (a) the obliviousness of the Causer, who is nonetheless [+VOL] [+INST] with respect to the causative microevent itself, but can also encode (b) the speaker's negative evaluation of Causer obliviousness. Observe:
(19) bo:se:
$<$ computer $>=$ ne'in
yisk'il
cat computer-PST
3SUBJ.break.3OBJ

'The cat broke my computer(/it).' 
When Is a Causative Situation not Mapped to a Causative Construction Proper? The Case of Hupa

\author{
[Natural, factual answer to 'What happened to your computer?'] \\ (20) bo:se:-mich'in'ding si-k'il \\ cat-because.of.3SG(LOW.ANIM) computer NEUT-break \\ Lit. 'The computer broke because of my cat.' \\ [Indicating speaker's annoyance at the cat. 'The cat broke my computer.']
}

A construction that primarily encodes (a) successful realization of a caused microevent with (b) a willing Causer-Agent ([+VOL][+INST], as above) that is nonetheless (c) oblivious with respect to the causative nature of the microevent is tantalizingly similar to yet crucially distinct from Song's (1996) conception of a PURP causative in two respects. The PURP causative is argued to be a construction encoding a situation of intended causation by a willing Causer (from which we can extrapolate $[+\mathrm{VOL}][+\mathrm{INST}]$ ), which nonetheless remains agnostic with respect to the outcome of the caused microevent: the speaker encodes the causative microevent (similarity) and Causer intentionality with respect to causation (difference), and remains agnostic as to whether the caused microevent was felicitously effected (difference).

\title{
6. Conclusion
}

The current work has offered an analysis of two constructions used in Hupa to encode causative situations that meet certain non-prototypical criteria. Dixon's (2000) typology takes into account 'causee willingness' to bend to the demands of the causative microevent, but not Causee involvement in said microevent, as such. Likewise, while Dixon discusses the intentionality of the Causer, intentionality of action vs. intentionality of explicitly causative action is not cleanly delineated. We have seen that Næss's (2007) model of transitivity as a prototype, in which participants are assigned feature values for volitionality; degree of responsibility (Instigation); and affectedness, has proven useful for explaining the distribution of the Hupa constructions.

This study is a preliminary data point, serving as a jumping-off point for investigating the distributional divide between causative constructions and less compact means of encoding causativity, including purpose clause constructions. It is hoped that case studies like these will help us flesh out an account of prototypical causativity, and, more interestingly, how human languages treat deviations from the prototype.

\begin{tabular}{llll}
\multicolumn{2}{l}{ Abbreviations } & & \\
1 & First Person & CLS & Classifier (Voice/Valence Marker) \\
2 & Second Person & DIMIN & Diminutive \\
3 & Third Person & DIR & Directional \\
ADV & Adverbial & HABIT & Habitual \\
ANIM & Animacy & INCEP & Inceptive
\end{tabular}




\section{Ramón Escamilla}

$\begin{array}{llll}\text { INDEF } & \text { Indefinite } & \text { PST } & \text { Past } \\ \text { NEUT } & \text { Neuter } & \text { SUBJ } & \text { Subject } \\ \text { OBJ } & \text { Object } & \text { THM } & \text { Thematic Verbal Element } \\ \text { PF } & \text { Perfective } & \text { REFL } & \text { Reflexive } \\ \text { POSS } & \text { Possessive } & \text { VOICE } & \text { Voice Marker }\end{array}$

\section{References}

Comrie, B. 1981. Language Universals and Linguistic Typology: Syntax and morphology [M]. Chicago: University of Chicago Press.

Dixon, R. M. W. 2000. A Typology of Causatives: Form, syntax and meaning [A]. In R. M. W. Dixon \& A. Y. Aikhenvald (eds.). Changing Valency: Case studies in transitivity [C]. New York: Cambridge University Press, 30-83.

Dryer, M. S. 1989. Large Linguistic Areas and Language Sampling [J]. Studies in Language, 13:257-292.

Escamilla, R. 2012a. The Syntactic Causative Construction in Hupa (California Athabaskan) [A]. Rice Working Papers in Linguistics, 3 [C].

Escamilla, R. 2012b. An Updated Typology of Causative Constructions: Form-function mappings in Hupa (California Athabaskan), Chungli Ao (Tibeto-Burman) and beyond [D]. PhD Dissertation. Berkeley: University of California.

Gil, D. 2001. Escaping Eurocentrism: Fieldwork as a process of unlearning [A]. In P. Newman \& M. Ratliff (eds.). Linguistic Fieldwork [C]. Cambridge: Cambridge University Press, 102-132.

Golla, V. 1970. Hupa Grammar [D]. PhD Dissertation. Berkeley: University of California.

Hetterle, K. 2015. Adverbial Clauses in Cross-Linguistic Perspective [M]. Berlin: Mouton de Gruyter.

Hopper, P. J. \& S. A. Thompson. 1980. Transitivity in Grammar and Discourse [J]. Language, 56(2):251299.

Huang, S-P. \& L. I-W. Su. 2005. Iconicity as Evidenced in Saisiyat Linguistic Coding of Causative Events. [J]. Oceanic Linguistics, 44(2):341-356.

Næss, Å. 2007. Prototypical Transitivity [M]. Amsterdam: John Benjamins Publishing Company.

Pardeshi, P. 2016. A Functional Account of Marathi's Voice Phenomena: Passives and causatives in Marathi [M]. Leiden/Boston: Brill.

Rice, K. 2000. Voice and Valency in the Athabaskan Family [A]. In R. M. W. Dixon \& A. Y. Aikhenvald (eds.). Changing Valency: Case studies in transitivity [C]. New York: Cambridge University Press, 173-235.

Sapir, E. \& V. Golla. 2001. Hupa Texts, with Notes and Lexicon [A]. In V. Golla \& S. O'Neill (eds.). The Collected Works of Edward Sapir [C]. Berlin: Mouton de Gruyter, 14:19-1011.

Shibatani, M. 1976. Causativization [A]. In M. Shibatani (ed.). Syntax and Semantics [C]. New York: Academic Press, 5:239-294.

Song, J. J. 1996. Causatives and Causation: A universal-typological perspective [M]. New York: Addison Wesley Longman Limited. 